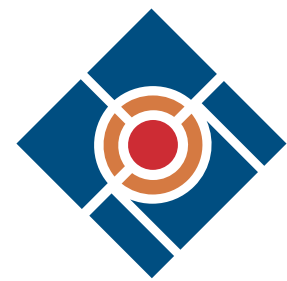

\title{
Wavy or curly?
}

Pupa U.P.A. Gilbert $\odot$

$\mathrm{P}$ opular hair styles are curly or wavy. A perfect example from the past was painted in Venus's wavy hair in "The birth of Venus" by Sandro Botticelli in 1483-1485 (Figure 1, left); a magnificent contemporary one was photographed in Beyoncé's curly afro hair during her Good Morning America concert in Central Park in July 2011 (Figure 1, right).

Which is better, wavy or curly? This is precisely the debate currently electrifying the diverse field of research in biomineralization. In this issue, the Addadi-Weiner group in SibonyNevo et al. argue that the elongated, curved single crystals in some mollusk shells are S-shaped, ${ }^{1}$ but other authors, including Willinger et al. $^{2}$ and Checa et al. ${ }^{3}$ argue that these crystals are helical. In other words, they are arguing for S-shaped wavy versus helical curly structures, to better describe the shell crystals. Who will win in the long term, Venus or Beyoncé? I am agnostic, maybe because my hair is straight, and because both sides of the debate have valid and logical arguments, so the answer is not trivial, and the question remains intriguingly open.

The shells in questions are made by small gastropods called pteropods that are abundant in open oceans all over the world, and invariably live near the water surface, where they swim by moving the wing-shaped feet that motivate their name. The pteropods include Creseis, Cuvierina, Cavolinia, and Clio, all of which make small, millimeter-sized shells out of aragonite $\left(\mathrm{CaCO}_{3}\right)$ crystals, which are transparent and densely packed, yet the shell density is low enough to enable the animal to float in water. The aragonite crystal fibers are elongated, $\sim 300 \mathrm{~nm}$ wide, tens of microns long (Figure 2a), approximately parallel to their neighboring crystals, and space-filling. The shape of these crystals is curved, which is unique among shell structures, including crossed-lamellar, ${ }^{4}$ nacre, ${ }^{5}$ prismatic, ${ }^{6}$ and foliated structures, ${ }^{7}$ all of which have elongated or flat singlecrystalline units that are straight, never curved. The crystal lattice may tilt, ${ }^{6,8,9}$ but the morphology of crystals never curves in all these other shells. The fantastic, curved aragonite fibers in pteropod shells appear prominently in SEM images of fractured shell cross-section surfaces. ${ }^{1-3}$ Their appearance, however, is consistent with both wavy or curly structures, because the precise path of a single aragonite fiber could not be followed, thus far, either by $\mathrm{SEM}^{2,3}$ or FIB-SEM reconstructions, as those presented in this issue by Sibony-Nevo et al. ${ }^{1}$

Clearly, new methods must be developed to address the wavy-curly question by looking at a single-crystalline fiber, or one hair, in the wavy-curly analogy. Possibilities include, but are not limited to, direct 3D SEM methods of an entire helical coil, if one can avoid breaking it by luck or by design, or FIB-SEM

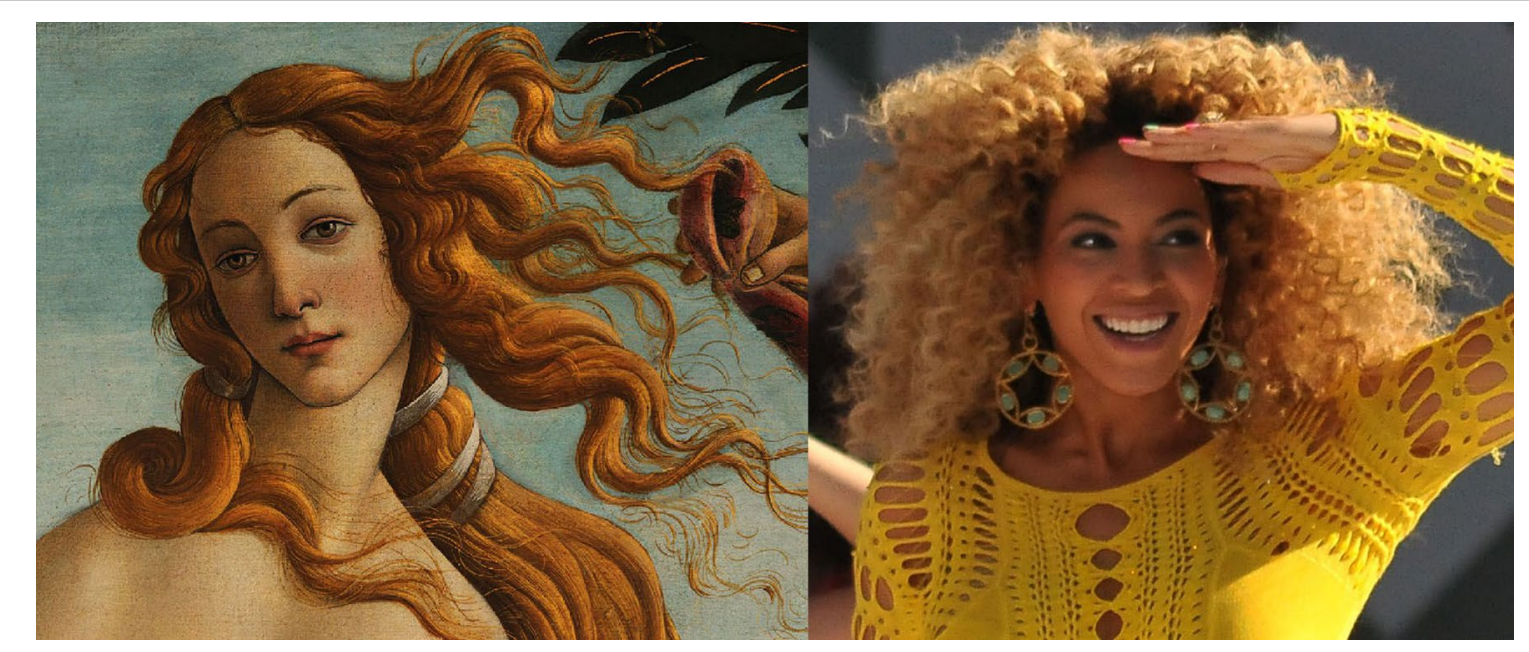

Figure 1. Credits: https://artsandculture.google.com/asset/the-birth-of-venus/MQEeq50LABEBVg?hl=en. https://commons. wikimedia.org/wiki/File:Beyonc\%C3\%A9_Knowles_GMA_Run_the_World_cropped.jpg.

This article was updated to correct Reference 1.

Pupa U.P.A. Gilbert, Departments of Physics, Chemistry, Geoscience, Materials Science and Engineering, University of Wisconsin, USA; Chemical Sciences Division, Lawrence Berkeley National Laboratory, USA; pupa@physics.wisc.edu

doi:10.1557/s43577-021-00229-7 


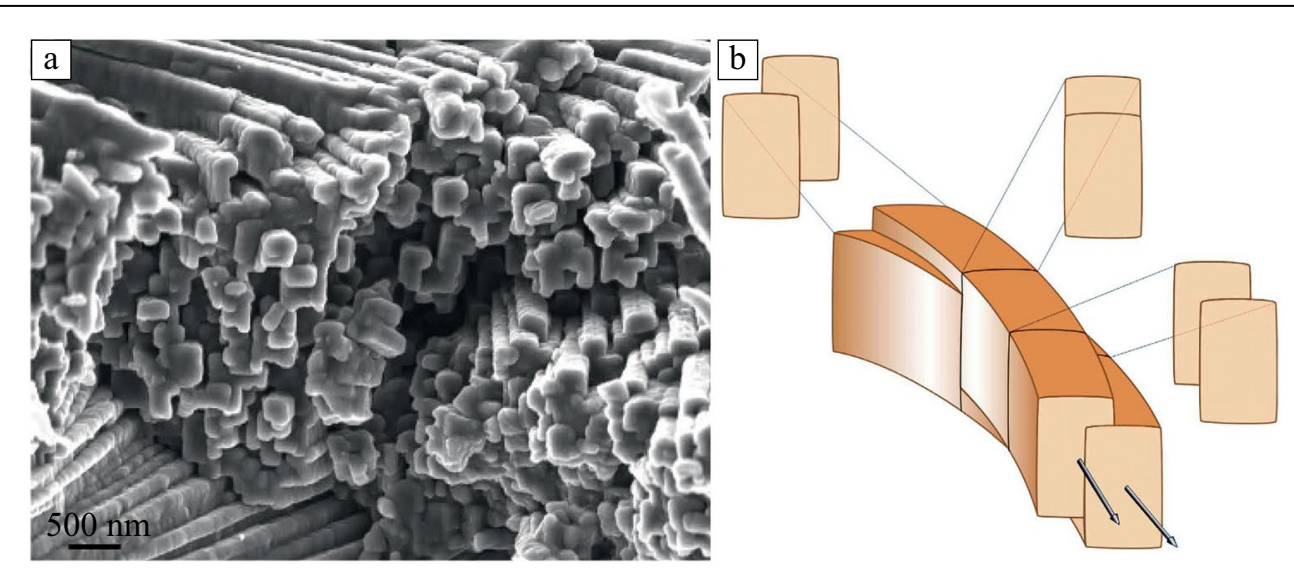

Figure 2. (a) The aragonite fibers are 300-nm wide and tens of microns long; their strange cross sections can be explained by the interlocking mechanisms in (b). Reprinted with permission from Reference 3. (C) 2016 Nature Publishing Group.

but the answer may suggest new, exciting ways to build synthetic structures, to achieve greater space-filling, or to pack more efficiently, or to build the perfect stackable chairs, or simply to understand the world in which we live, one new complicated structure at a time.

\section{Funding}

Funding was provided by DOE-BES-CSGBGeosciences (Grant No. DE-FG02-07ER1

images with higher resolution so that single aragonite fibers can be easily followed, or an entirely new method to make a single aragonite fiber denser than all others in nano-tomography, or insoluble while all others are soluble in acid. For now, a method that can conclusively clarify the structure was not found.

Intriguing new data from FIB-SEM show S-shapes, but these could still be part of adjacent helices. From one FIB section to the next, the fibers remain parallel, which certainly suggests S-shapes as Sibony-Nevo et al. concluded, ${ }^{1}$ but is also consistent with fibers originating from adjacent sets of helices. How is this possible?

Unlike wavy or curly hair, the aragonite fibers in pteropod shells fill space. They do so by crossing each other, as shown by Checa et al. ${ }^{3}$ and in Figure $2 b$. The unique cross sections of adjacent fibers, observed by all authors, are perfectly consistent with the model of Figure $2 b$.

If one further assumes that each fiber has its own helix, with identical radii of curvature of $\sim 10 \mu \mathrm{m}$ in all helices and parallel but distinct axes for each fiber, then, interlocking fibers can easily fill 3D space. This only requires fiber interlocking, which clearly happens, is seen by all authors, and is shown in Figure 2b.

Of course, the fact that helical structure can happen does not mean that it does, nor that pteropods evolved to form curly or wavy structures for a specific materials science reason, for instance, because either curly or wavy fibers confer better materials performance to the shell. To demonstrate an evolutionary advantage, we need model systems in which we can change the structure and compare mechanical properties. That will be the ultimate understanding of evolution, measurable, quantitative, and predictable as Darwin intended, and as only materials scientists can and will contribute.

In conclusion, who will win the wavy-curly debate for pteropod shell crystalline fibers, Venus or Beyoncé? We don't know,
5899) and NSF-DMR-BMAT (Grant No. DMR-1603192).

\section{Open access}

This article is licensed under a Creative Commons Attribution 4.0 International License, which permits use, sharing, adaptation, distribution and reproduction in any medium or format, as long as you give appropriate credit to the original author(s) and the source, provide a link to the Creative Commons license, and indicate if changes were made. The images or other third party material in this article are included in the article's Creative Commons license, unless indicated otherwise in a credit line to the material. If material is not included in the article's Creative Commons license and your intended use is not permitted by statutory regulation or exceeds the permitted use, you will need to obtain permission directly from the copyright holder. To view a copy of this license, visit http://creativecommons. org/licenses/by/4.0/.

\section{References}

1. 0. Sibony-Nevo, K. Rechav, V. Farstey, E. Shimoni, N. Varsano, L. Addadi, S. Weiner, MRS Bull. 47(1) (2022). https://doi.org/10.1557/s43577-021-00184-3

2. M.G. Willinger, A.G. Checa, J.T. Bonarski, M. Faryna, K. Berent, Adv. Funct. Mater. 26, $553(2016)$

3. A.G. Checa, E. Macías-Sánchez, J. Ramírez-Rico, Sci. Rep. 6, 25989 (2016)

4. J. Currey, A. Kohn, J. Mater. Sci. 11, 1615 (1976)

5. R.A. Metzler, D. Zhou, M. Abrecht, J.-W. Chiou, J. Guo, D. Ariosa, S.N. Coppersmith, P. Gilbert, Phys. Rev. B 77, 064110 (2008)

6. I.C. Olson, R.A. Metzler, N. Tamura, M. Kunz, C.E. Killian, P.U.P.A. Gilbert, J. Struct Biol. 183, 180 (2013)

7. R.T. DeVol, R.A. Metzler, L. Kabalah-Amitai, B. Pokroy, Y. Politi, A. Gal, L. Addadi, S. Weiner, A. Fernandez-Martinez, R. Demichelis, J.D. Gale, J. Ihli, F.C. Meldrum, A.Z Blonsky, C.E. Killian, C.B. Salling, A.T. Young, M.A. Marcus, A. Scholl, A. Doran, C. Jenkins, H.A. Bechtel, P.U.P.A. Gilbert, J. Phys. Chem. B 118, 8449 (2014)

8. A.G. Checa, J.T. Bonarski, M.G. Willinger, M. Faryna, K. Berent, B. Kania, A. González-Segura, C.M. Pina, J. Pospiech, A. Morawiec, J. R. Soc. Interface 10, 20130425 (2013)

9. V. Schoeppler, D. Stier, R.J. Best, C. Song, J. Turner, B.H. Savitzky, C. Ophus, M.A. Marcus, S. Zhao, K. Bustillo, Adv. Mater. 33, 2101358 (2021) 